\title{
Advising for Sustainability: A Challenge
}

\author{
Cheryl Wanko, PhD \\ Professor of English \\ Chair, Committee for Advising Excellence, West Chester University \\ Email: cwanko@wcupa.edu
}

\begin{abstract}
Our society needs sustainable solutions to unprecedented and interconnected environmental, social, and economic problems. Advisors must join campus colleagues who are incorporating sustainability into institutional operations and curricula by engaging in "advising for sustainability." This article first provides practical ways to take advantage of the unique opportunities offered to advisors by recommending and discussing academic options related to sustainability. It also interrogates advising's teaching function and suggests that, by adapting critical pedagogy to our advising practices, we can engage in reflective advising conversations that probe our institutional complicity in global environmental crisis and urge our students to interrogate their behaviors and goals to embrace more sustainable ones.
\end{abstract}

\section{Introduction}

According to NACADA, advising is "a teaching and learning process" ("Concept of Academic Advising"). In both classrooms and offices, faculty and advisors constantly scrutinize what and how we teach. Advising sessions transmit rudimentary information such as program requirements and inculcate autonomy skills such as time management, helping our advisees through college transitions and preparing them for lifelong personal development. Beneath these lessons, however, lie larger assumptions about how our world is organized and where our students fit in. Often, both courses and advising sessions are conducted within the boundaries of

\footnotetext{
${ }^{1}$ Literature on EfS - also referred to, with slight variations in meaning, as Educating for Sustainable Development, Sustainability Education, and Ecopedagogy - has burgeoned since the 1990s. Two essay collections that provide good overviews are Barlett and Chase's Sustainability on Campus: Stories and Strategies for Change
}

these assumptions, as though they were commonsense and natural: within a paradigm, which, being unobserved and unquestioned, self-replicates. But what if our paradigm consigns our students to a future of mass extinctions, devastating human health impacts, and unpredictable planetary crises such as climate change and ocean acidification? Clearly, if we conduct our teaching without critically examining the assumptions that uphold this paradigm, we are shirking our responsibility to empower our students to shape futures in which they can thrive. Faculty involved in Educating for Sustainability (EfS) in classroom curricula hope that we are encouraging or reinforcing such deep critical thinking. ${ }^{1}$ This article argues that advising can-and must-contribute to this project by promoting a complementary effort that we can call, somewhat unoriginally, "Advising for Sustainability" (AfS). I write this in the hope that, through an advising practice that is attuned to AfS, advisors and students alike might cultivate more sustainable behaviors and life perspectives to help alter our culture's self-destructive course.

What is sustainability? In the only significant article on the interconnections between advising and sustainability, Jennifer Joslin refers readers to the widely-cited 1987 "Bruntland" definition: sustainability "meets the needs of the present without compromising the ability of future generations to do the same" (276). Sustainability subsumes environmentalism by acknowledging that, to preserve the environment, we must address culture and the economy because "a world in which poverty and inequity are endemic will always be prone to ecological and other

and Jones, Selby and Sterling's Sustainability Education: Perspectives and Practice Across Higher Education. 
crises" (276). To capture this interdependence, sustainability is traditionally pictured as three "pillars" or as Venn diagrams [see Figures 1.1-1.4]:

Figure 1 - FOUR MODELS - SUSTAINABILITY DEFINITIONS

\subsection{Pillars}

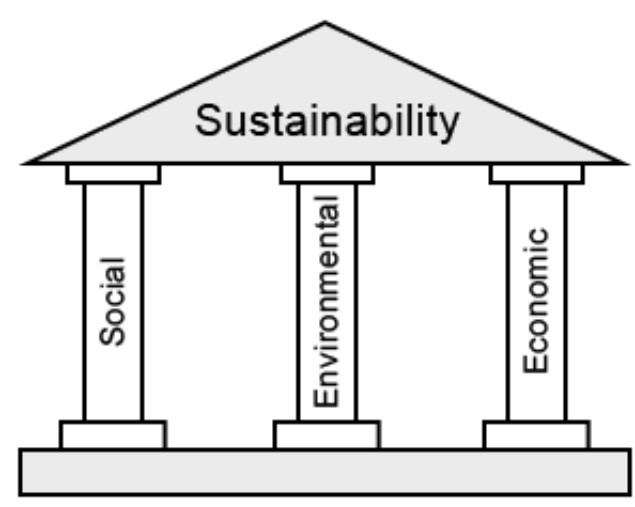

\subsection{Venn}

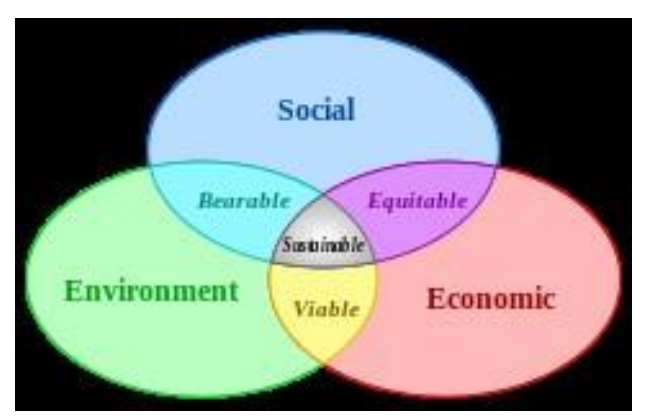

\subsection{Nested Venn}

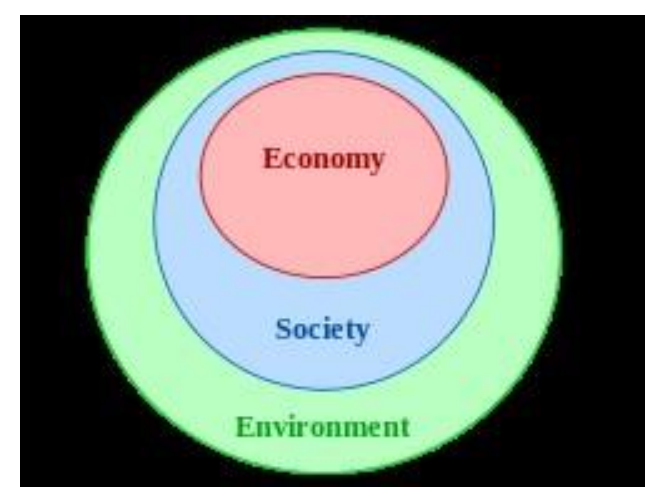

1.4 Nested Venn

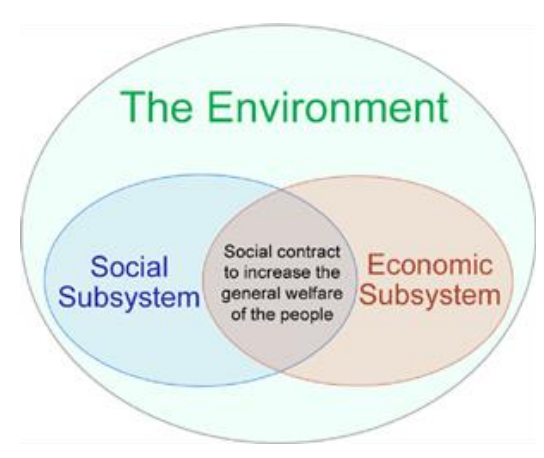

To meet the needs of future generations, we must recognize how these components interact today. For example, controversies arise when economic interests are pitted against environmental and sociocultural ones: endangered species v. land development, emissions requirements v. car company profits, Native American water rights v. the DAPL pipeline, among many others. Major sources of pollution, such as the garbage incinerators and other heavy industry that cause high rates of asthma and cancer, are often located in "sacrifice zones," lower-income areas populated by people of color. Interrelations between the three components cause sustainability advocates to believe that our current economic system, which values consumerism and unimpeded growth, must transform into a system that embraces other goals, such as health, equity, and sufficiency. ${ }^{2}$

\footnotetext{
2 The quickest, most accessible introduction to sustainability problems and solutions continues to be Annie Leonard's video, The Story of Stuff.
} 
It stands to reason, then, that institutions of higher learning, whose missions serve the future, should lead the way in that transformation. Many universities, as Joslin notes, have begun examining their physical plants and office processes to begin addressing such change (277-280), and others have divested their endowments of fossil fuels. The Association for the Advancement of Sustainability in Higher Education (AASHE) and other organizations help institutions evolve via reporting systems. Campuses have begun following the lead of renowned EfS programs such as Emory's Piedmont Project. Articles in New Directions in Student Services (Dunn and Hart-Steffes, Kerr and Hart-Steffes) have praised the recent introduction of sustainability into their professional Student Affairs discussions. Changing baseline assumptions within institutions that must themselves perform within larger systems is a daunting challenge, but one that many have accepted. In this light, our question becomes, "Where, then, does academic advising fit?" How can we join our colleagues and create daily advising practices that increase sustainable habits and raise awareness of the environmental crisis facing us all?

Neither of the main professional organizations have yet provided direction, as NACADA does not mention sustainability and AASHE does not mention advising. Additionally, advising does not appear in scholarly EfS materials or popular titles such as William M. Timpson et al.'s 147 Practical Tips for Teaching Sustainability. A review of advising literature shows that articles and NACADA conference presentations that discuss diversity are beginning to address social justice but do not yet connect that project to the environment. ${ }^{3}$ Any applications of sustainability to advising focus on physical materials-going paperless, doing energy audits, recycling, and attending virtual conferences (Joslin, Bucci et al.)-and while such changes must occur, they do not speak to the crucial teaching work of advising that NACADA identifies as its core mission.

Higher education leadership bodies seem to urge advisors to take on this complex teaching, but they do not yet make it explicit, nor do they extend their educational aims to their potentially radical

\footnotetext{
3 For example, Lanta, Burton, Arnsperger Selzer \& Rouse.

4 Non-traditional students present another set of challenges. I am aware that most of my comments here refer
}

conclusions. In its sections on advising, The Council for the Advancement of Standards in Higher Education expects advising administrations to "incorporate sustainability practices in the management and design of programs, services, and facilities" ("Academic Advising Programs"). They also support a pedagogical approach that would help students "clarify educational, career, and life goals." Further, the CAS Standards ask institutions to prepare students for "their careers, citizenship, and lives" by encouraging the development of "social responsibility, global perspective, and sense of civic responsibility" ("Academic Advising Programs"). Though it doesn't single out advising, the American Association of Colleges and Universities' LEAP initiative also stresses the need for institutions of higher learning to nurture student civic-mindedness through "engagement with big questions, both contemporary and enduring" (An Introduction to LEAP 3). Big questions, however, often lead to big conclusions. To quote the title of Naomi Klein's book on climate change: "This changes everything." And so a need arises in EfS, and thus for AfS, for a pedagogy that obliges both advisors and advisees alike to question everything, including the purposes and potential complicity of the institutions in which they find themselves.

This article's central query now becomes clear: how might academic advising embrace the challenge of teaching our students the intellectual and emotional competencies they will need in a world-including their universities-built upon unsustainable systems? At least two practical difficulties present themselves immediately. First, many of us already struggle under massive advising loads (or, for faculty advisors, advising loads on top of teaching loads), and often just getting students to take the correct courses in the correct order is a big enough job. How can one expect advisors also to engage with students regarding something that seems as ancillary as sustainability? Second, our students themselves may want only basic course sequence and policy information. Pressed for time and dealing with the distractions of young adulthood, they may not welcome dialog on sustainable life choices. 4 This article thus presents a range of options for experiment-

to traditional-age students and that older populations, especially, will require other approaches. 
ing with our advising practices, from quick to prolonged, and from superficial to profound. I begin with some fairly simple suggestions and then move to ways in which both advisors and advisees can collaborate on sustainability problem-solving by infusing our teaching practices with insights from critical pedagogy.

Advisors want their students to move through and beyond their college careers with an ever-increasing ability to take on life's challenges. As EfS proponents Arjen Wals and Bob Jickling state, "If the integration of sustainability in higher education is closely connected to the development of emancipatory qualities [in our students and society] it will need to provide students with a way of understanding and transforming the complex world of which they are part" (225). But classroom teaching cannot do this hugely important job alone. Advisors have the enviable one-on-one opportunity to make sustainability personal, meaningful, and hopeful for our students and to allow them to grow in ways less harmful to the earth and its inhabitants.

\section{Basic Approaches}

Let's assume you've done the easy "greening" of your office and work habits. You have adopted electronic advising tools, and you minimize use of fresh (recycled) paper. You turn off unnecessary lights and electronic equipment. You don't use single-serve bottles in your office; you avoid take-out containers; and you carry your own hand towel to your bathroom visits. You try to walk, carpool, bike, use public transportation, or work from home as much as your institution will allow. Through these actions, you are reducing your material impact, which is what all campus citizens should do daily. While sustainability activists argue that discrete individual actions like these will go only so far without political, industrial, or society-wide change, such actions are where we all must start. They add up, and by performing them matter-of-factly, other advisors and administrators, students, and faculty observe and add your practices to their mental menu of possible ways to conduct quotidian tasks. Your green habits allow others to imagine a "new normal."

But when your students arrive for their appointments, how can you help them see the importance of and motivations for such actions? Of course, you can explain your rationale, casually or deliberately, depending on your relationships with your students. You might adopt a brief "I choose not to use single-serve because of the waste it produces," or you might prefer something stronger: "I gave up bottled water when I learned about the great Pacific plastic patch, the marine animal deaths from eating plastic, the corporations that steal public water sources, and the climate impact of transporting water." You can add that you're not just doing it "for the earth," but for other people, as well. The second approach is not for everyone; it might be interpreted as guilt-inducing or self-righteous. However, in either case, a light touch can help minimize negative reactions, as can remembering that most unsustainable actions derive from lack of knowledge.

Your advisee must plan for next semester and they may have many class options within their curricula. As a good advisor, you know about these options, but do you know which ones highlight sustainability? One of NACADA's core competencies for advisor proficiency is "informational," which means we must be familiar with "Curriculum, degree programs, and other academic requirements and options." For AfS advisors, that competency should include familiarity with sustainability courses across disciplines. If you and your advisees discover that your institution offers few sustainability classes, you can ask why this is the case, or why sustainability, inherently interdisciplinary, isn't distributed evenly across the disciplines. Connecting with the EfS faculty and sustainability committees on your campus can help you work for change and strengthen broader institutional efforts. Posting a list of those courses that do exist on your advising website (or another university site), distributing that link, or making the list otherwise accessible will raise the profile of the classes and facilitate your discussions with advisees and colleagues. Faculty advisors especially must exert themselves to learn about and publicize the sustainability options that lie outside their own departments. And while it's easy to recommend sustainability choices to already-curious students, an AfS advisor's mission must include promoting them to the rest. These students may not be interested, but advisors recognize that the more likely explanation is that they simply are not aware of the availability of such courses. Important conversations can follow from this basic information. 
The AfS content material you can make available to your students will also include sustainability-related internships, service-learning and volunteerism, films and lectures, and student groups. If your students do choose sustainability-related classes or other activities, follow up on them in subsequent advising appointments. Ask them what they learned from that urban gardening internship or that "Ethics and Environmental Justice" class, and ask them how the experience impacted the way they live. Have they changed as a result? Why or why not? Janet K. Schulenberg notes the importance of such open-ended questions: "In addressing complicated areas of student inquiry, advisors can employ reflective conversation techniques that encourage students to think through complex situational issues and identify their own interpretations and solutions" (125). Such conversations can lead to the more complex approaches to AfS methodology that I broach in the next section.

\section{Using Critical Pedagogy to Link EfS with AfS}

Recommending sustainability classes and raising follow-up questions begins the process of shifting advising practices to a model that foregrounds sustainability. The form of advising that limits itself to informational exchange is what Burns B. Crookston called "prescriptive" advising and Marc Lowenstein called "bookkeeping." It is also what Paulo Freire, one of the originators of the critical pedagogy movement, famously called "the banking model" of education. By this he means a one-way transaction in which the teacher is assumed to have all of the knowledge, power, and agency, and the student has none: "Education thus becomes an act of depositing, in which the students are the depositories and the teacher is the depositor. Instead of communicating, the teacher issues communiqués and makes deposits which the students patiently receive, memorize, and repeat" (53). Such an approach clearly limits the efficacy of teaching, just as it does of both advising and EfS, the latter of which enjoins us to move beyond education about sustainability to education for sustainability. Critical pedagogy and EfS both aim to shift our paradigm to one that undergirds a more just and healthy world. In its concern for the whole student, advising would seem to have a similar aim, though advising has not yet realized its potential as a social change agent. In this section, I propose some theoretical foundations based in critical pedagogy upon which AfS can develop, and I suggest some practical applications.

The literature on critical pedagogy and its controversies is vast, and so I can only address it in broad strokes here. A solid preliminary definition comes from Barry Kanpol, who states that critical pedagogy:

refers to the means and methods that test and hope to change the structures of schools that allow inequalities and social injustices. Critical pedagogy is a cultural-political tool that takes seriously the notion of human differences ... In its most radical sense, critical pedagogy seeks to unoppress the oppressed and unite people in a shared language of critique, struggle, and hope to end various forms of human suffering. ... Finally, critical pedagogy also addresses how one's beliefs and faith are embedded in schooling. (27)

Its radical emancipatory agenda's main tenets and methods include:

- understanding educational institutions and the educational process themselves as political

- helping students and teachers alike to awaken and nurture a critical consciousness

- decentering classroom authority to disrupt the "banking" model

- replacing that model with a problem-posing model

- using the real materials of students' lives as the curriculum

- empowering students to create a more democratic and just society. (Aliakbari and Faraji)

Critical pedagogy's clearest connections with current advising scholarship lie in the work that recommends adjusting our practice to our students' race, gender, sexual orientation, and class status to help them succeed academically; possible methods for amplifying advising's social advocacy possibilities via a critical approach have only recently been argued for by Andrew Puroway. Theoretically, this will allow minority group students equal access to the rewards of education that majority group students receive. However, this is problematic from a critical pedagogy perspective in that the process does not change the embedded power relations that caused the inequities to begin with. For example, 
NACADA's conceptual competency wants advisors to understand "How equitable and inclusive environments are created and maintained" ("Core Competencies"), but lacks the subsequent step that would charge advisors with actually creating them.

Further, neither classic critical pedagogy nor advising explicitly links its educational or social aims to how schools have helped precipitate the planetary crisis. For example, no advising scholarship has yet mentioned that one reason to make sure vulnerable groups are educated and empowered is that an environmental disaster like climate change will impact these populations hardest: people of color, the poor who live in threatened land with no means to move, those whose cultures do not capitulate to global neoliberalism. We have not examined how to help our minority students who may have been subjected to environmental racism and thus may have more health problems or environmental stressors which result in negative academic consequences. In critical pedagogy, Moacir Gadotti, a colleague of Freire, later made the obvious connection and pointed to the central paradox inherent in the idea that more education means more sustainability:

Nowadays, people who are the most educated are the ones who are harming the planet because of their unsustainable lifestyles. The countries that offer the most access to education are the countries that have in their history, habits and values that are deeply harmful to life on the planet. Education is more a part of sustainable development's problem than part of its solution because it re-enforces the principles and values of an unsustainable economy. (22)

As C.A. Bowers has pointed out, if any pedagogy including critical pedagogy and advising-as-teaching - simply educates to help students climb to the level of consumption, technophila, and destruction that the global north has achieved, we will not solve our sustainability problems.

This is why Gadotti, Bowers, and Richard Kahn, among others, have merged critical pedagogy with EfS, envisioning:

the achievement of a just and free world with a future-oriented ecological politics that militantly op- poses the globalization of neoliberalism and imperialism, on the one hand, and attempts to foment collective ecoliteracy and realize culturally relevant forms of knowledge grounded in normative concepts such as sustainability, planetarity, and biophilia, on the other. (Kahn 18)

Kahn sketches a political mission for EfS that would help us move our students and institutions beyond monoculturism, teleology, and anthropocentrism to consider the future in their present activities. Certainly, advisors advise with an eye to their students' individual futures; AfS would push us to extend this to the health and prosperity of the collective.

AfS can best mobilize its liberatory capacity through NACADA's "relational" core competency, which refers to cultivating productive ways for advisors to relate to their advisees. NACADA's current articulation of this competency evinces a "banking model" foundation in its definition that advisors "convey the concepts and information from the [informational and conceptual] components to their advisees," yet then elaborates to describe an inclusive, respectful, and problem-solving relationship, more in line with critical pedagogy, which recommends sharing classroom authority and cultivating students as co-teachers who draw from and critique the authentic material of their own experiences. The AfS relationship exposes both advisors and advisees as unwilling (or unconscious) participants in their shared unsustainable culture. As far back as 1980, Linda Shaw Finlay and Valerie Faith testified to their students' frustration:

our students fear and distrust the culture that runs the schools, a culture which they perceive as subordinating individual activity to the needs of a consumer economy. Since our students are not children, however, their education is complicated by their awareness that they have become accomplices in maintaining this culture and its values. They want those consumer goods, they want the college degree for earning power, political power, social power of many kinds. We and our students had to face the contradiction between the values of the consumer society ... and their "childlike" instinct for personal determination that made them want to turn away from the institutions of this society. (35) 
AfS positions us as collaborators in this problemposing scenario of fulfilling students' goals in ways that do not further planetary degradation-and thus decrease other current and future students' opportunities of fulfilling their goals.

We can do this through the meaningful reflective conversations that we often conduct to, in NACADA's words, "facilitate problem solving, decision-making, meaning-making, planning, and goal setting" ("Core Competencies"). Unfortunately, the meaning students have so far made of their lives often lies within the conceptual paradigm of a neoliberal upbringing. By asking students what they expect to gain from their higher education experience and what they believe it delivers, we can expose them to the painful paradoxes both Finlay and Gadotti identified to begin the mental shifts that must precede the structural ones.

Meaning-making helps us help students adjust their vision to evaluate their past goals, examine their motivations, and consider new options. And since, according to Osbaldiston and Sheldon, psychologists who have studied motivations to environmental action, goals "can have a significant role in prompting and guiding patterns of complex behavior over time" (350), goal adjustment is crucial to the AfS project. AfS advisors must listen to the way students explain their motivations and goals and help them to interrogate them via sustainability, because goals "have the capacity to initiate entirely new patterns of behavior, thus creating entirely new experiences and discoveries for people" (Osbaldiston and Sheldon 350). For example, the AfS critical pedagogue might ask students to question how their chosen major prepares them to make the world more sustainable for themselves and others-or prepares them to survive in a world that will confront them with the climate change, displaced populations, and increasingly polluted natural resources. An AfS advisor would prompt them to expose and resolve the tension between their career aims and sustainability. In many cases, both students and advisors may find the problem unsolvable: there may be, for example, no healthy way to redirect what and how marketing majors learn. The project then continues on an indi-

\footnotetext{
5 Sustainability-minded language scholars could join
} queer theorists to examine how advisors use normative vidual and institutional level: the student must painfully confront their unsustainable choice, and the advising center must promote a relationship with marketing faculty to urge them to critique and align their goals with EfS.

Janet K. Schulenberg notes, "advising situations naturally include discussions of how students come to know themselves and their world, personal beliefs, and relationships with others" (122). ${ }^{5}$ Since college provides a laboratory for young adults to question the values they brought with them to the institution, AfS advisors provide a safe, one-on-one space where values can be examined in relation to how they contribute to unsustainable conditions. Good advisors of any stripe do not impose their values on advisees: that would more resemble the imperious banking model that critical pedagogy decries. Critical pedagogy proposes the kind of active problem-solving pedagogy that allows students' critical consciousness to self-actualize, and EfS aims to empower learners "to transform themselves and the society they live in" ("What is EDS?"; emphasis added). Like a critical pedagogy practitioner, Schulenberg suggests conducting reflective advising conversations through open-ended questions and working with students as collaborators. She asserts that "advisors need to refrain from offering solutions to problems and instead focus on helping students discover their own paths to success" (125). Additionally, AfS advisors will enable the processes that cause students to critique their definitions of success and possible paths to it. For best results in all kinds of instruction, we must be "autonomy-supportive" (Sheldon et al. 262), but, as AfS advisors, we need to make sure that the student's autonomous self is examining itself critically, so that the values implicit in sustainability-equity, sufficiency, interdependence, concern for the commons, etc.-receive the attention they usually do not. Students' pre-existent and emerging value systems must be respected, but students also need to understand how those values support or impede constructive change in larger social, political, environmental, and economic structures.

Decentering the advising relationship requires that we advisors must confront our own assumed values, as well. White advisors with minority

words such as "naturally," which are culturally loaded. However, that analysis is for another article. 
advisees and straight advisors with queer advisees are urged to recognize when they are implicitly endorsing a norm, and, if conscientious, they work to correct these biases. We project norms that perpetuate environmental destruction, as well-definitions of "success," for example, that we unconsciously deliver via our vocabulary and questions, and that our institutions reinforce through, for example, the alumni they honor. We must admit our complicity in the self-replicating systems of education and larger culture that piles up waste and decimates species, and we must be familiar enough with alternatives to provide hope. We can only nurture autonomy in our students through the critical self-analysis that reveals the culture-bounded limits of our own autonomy. Through this, AfS can reveal directions and possibilities that advisors themselves may not have yet imagined.

An AfS advisor can enact self-actualizing problem-solving pedagogy by intentionally foregrounding cultural assumptions that students may not see. One might interrogate students' preconceived ideas of "the good life," for example, by displaying a screen with the infographic that summarizes a 2014 survey by the Center for a New American Dream. The Center's results showed surprising support for a dream that placed values like "being in harmony with nature" above those like "achieving affluence." I have often showed it to my advisees and asked them which goals best match theirs [See Figure 2]:

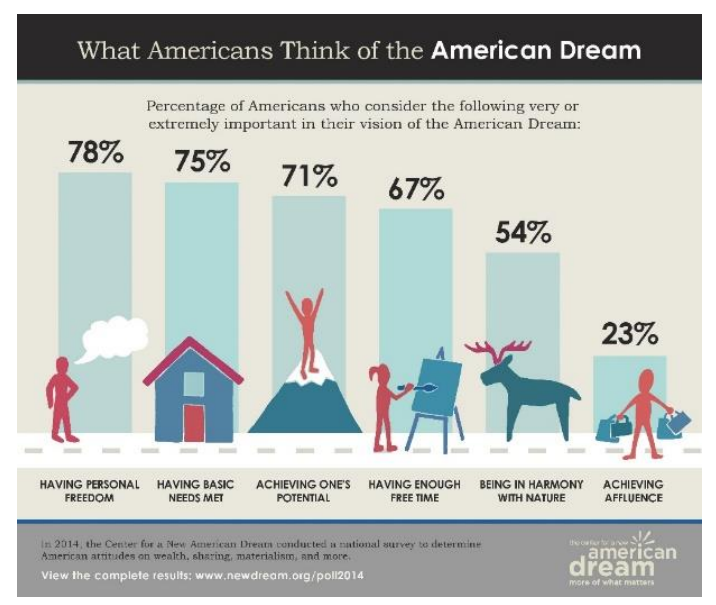

One can ask where they believe they developed such values, and whether or not such values are good for them, their families, their communities, and the world. We can help our students analyze whether consumerism and the "growth" economy will lead them to their conception of the good life. Of course, we all want a certain amount of material comfort, but we need to examine our definitions of "enough," while introducing the idea that sustainability does not mean deprivation.

Perhaps our students come from backgrounds of material insufficiency, and, understandably, don't want that insecurity to continue. We might explore with these students, then, how systems like education, zoning, healthcare, law, and banking operate to keep people in deprived positions, so that their future success aids in transforming these systems. For, as Freire recognized, "almost always, during the initial stage of the struggle, the oppressed, instead of striving for liberation, tend themselves to become oppressors ... The very structure of their thought has been conditioned by the contradictions of the concrete, existential situation by which they were shaped" (27). Using a sustainability-inflected range of goals as well as analytic methodology, advisors and advisees can ask whether or not the advisee's current academic trajectory will help lead them where they really want to go. Other students find themselves paralyzed, not believing that their individual efforts can affect the state of the world. They bring with them to university lives that, in literary scholar Carolyn Merchant's words, "are shaped by the stories we hear as children; some fade as we grow older, others are reinforced by our families, churches and schools. From stories we absorb our goals in life, our morals, and our patterns of behavior" (3). "No Impact Man" Colin Beavan's book How to be Alive recommends unpacking the stories that undermine our agency and contribute to a vitiated world. Its exercises for exposing these stories are inspirational starting points for our deeper advising discussions (44-58).

Just like classroom teachers, AfS advisors will inevitably encounter resistance and denial. Both offer important lessons for both advisor and advisee. Many of our middle-class advisees desire advisors only to deposit information into them so they can schedule classes and get on with their lives. While we are used to intervening in that simplistic, transactional relationship, such an encounter also reveals to us the advisee's assumption that their goal is to accept and advance in the current system. Taking time 
with such students can help reveal to them basic assumptions: for example, that ecological crisis may destroy the type of world in which they plan to thrive. Other student populations may have culturally-determined attitudes that do not include or run counter to sustainability. For example, first-generation students may echo the popular notion that sustainability and economic success are oppositional, that environmental action stifles the good jobs they are in college to prep for. One-on-one advising can begin unpacking the complex socioeconomic circumstances of these misunderstandings. One might wonder aloud, "Doesn't it seem strange that many job choices seem to require damaging our natural environment? Why do you think things are set up that way?" Familiarity with some of the scholarship that examines and debunks the economy-v.-environment myth can help. ${ }^{6}$

A colleague of mine at a campus in the heart of natural gas fracking country once spoke movingly about a student whose family had to abandon farming and open their property for drilling. This student not only deserves sympathy and comfort, but also the critical insight that talking about the larger systems of sustainability brings. She senses that something is wrong with agricultural, land-use, and industrial policies that destroy family farms and livelihoods; classes in sustainability and discussions with advisors who know about the heartbreaking dilemmas with which unsustainable systems confront people can help students analyze these situations so that they can work for change, if they so desire. Other advisees who have benefited from unsustainable practices like fracking may become defensive when questioned about the systems upon which they and their families depend (and that may have enabled them financially to attend our institutions). Noting the diverse effects of fracking might allow such a student to see that not everyone benefits: one might tell this second student the story of the first. Like all good advisors, an AfS advisor always employs relational competencies to preserve the learning relationship so that the student - and sustainability - are best served.

EfS scholars Wals and Jickling would frame our advising work as part of a larger institutional mission to "develop in their students the competencies which will enable them to cope with uncertainty, poorly defined situations and conflicting or at least diverging norms, values, interests and reality constructions" (224). Schulenberg states: "due to the supportive, relationship-oriented nature of their work, advisors are ideally situated ... to provoke students to tackle questions that lack clear-cut answers" (125). Thus, AfS-led speculation is positioned perfectly to help. Our advisees will have a lot on their plates because of the bad choices we have made. AfS advisors should acknowledge but not fixate on our complicity, since research has shown that the fearbased messaging does not spur action (O'Neill and Nicholson-Cole 361-64) and since, as advisors, we focus positively on the possibilities lying before our students. Thus, we should join our critical pedagogue colleagues in helping our advisees engage in "futures thinking" so they imagine the type of society they want to inhabit and then pursue the academic opportunities they will need to make their vision real.

\section{Conclusion: Our Futures in AfS}

In the third of its three competencies, NACADA recommends that advisors master the "conceptual" dimension, which "provides the context for the delivery of academic advising. It covers the ideas and theories that advisors must understand to effectively advise their students." This conceptual competency welcomes the kind of reconfiguration of our teaching mission that I recommend here. For example, advisors are exhorted to learn "the history and role of academic advising in higher education," and to examine "expected outcomes of academic advising" ("Core Competencies"). Yet for AfS, our understanding of this competency must move beyond its current bounds. Infused with the structural questioning that critical pedagogy mandates, advisors must explore how the "history and role" of advising has also greased the machinery of planetary destruction. Our advising outcomes, then, would be recast as ways of preparing students for their challenging futures: resiliency, questioning, understanding of injustice, knowledge of political agency, and activism.

\footnotetext{
${ }^{6}$ See, for example, the work of Paul Hawken, Eban

Goodstein, or the late Stephen M. Meyer.
} 
Our main steps for building a culture of AfS would begin with:

- enacting the basic approaches of sustainable practice while pointing out to our advisees why we do them

- provoking reflective, critical conversations with our advisees

- engaging in critical reflection on our own personal and professional practices

- forging relationships with EfS faculty and other sustainability groups

- exposing all individual and institutional structures' links to larger systems of our unsustainable society and working to change them.

In following these steps, all of our practices will be illuminated. We will not blindly hand out plastic pens and pins to "brand" our advising centers because we'll know the harmful effects of such detritus and, further, we will have questioned and resisted the consumerist assumption that people will not value an office or activity unless they receive a souvenir.

We must take heart in knowing that we are joining communities of others who are also searching for a way forward. In fact, the recognition of community presents one of the most difficult - yet fulfilling - ways we need to reorient our advising practice. AfS will require that we decenter not only our own but also our advisees' position as we transition advising from a sole focus on the individual without regard for the community. Advising which helps students develop their own agency all too often forgets to remind them that they are part of communities, and a world, that needs them to express their individuality in ways healthful to both. As we do this, we challenge one of the core beliefs of our consumerist culture, that personal desires are paramount and must not be controverted. AfS treads gently here, as we remind advisees of their inherent biophilia, love of all living things, and that, in attaining their dreams, the lives of other people and species depend on their decisions. We can offer to them, in Henry Giroux's words, a vision of "a self-constituted authority that expresses a democratic conception of a collective life, one that is embodied in an ethic of solidarity, social transformation, and an imaginative vision of citizenship" (95).
Advising has been slow to interrogate its roles in confronting power and initiating change with regard to planetary health. It is time to incorporate a deeper and more critical pedagogical theory into our advising curriculum via AfS, because our mission requires us to prepare students properlyand they can no longer base their goals on systems in crisis. In advising as in classroom teaching, we need to find more conscious and comprehensive ways for students to reconceptualize their visions of their and their societies' futures. In this, advising has a huge and unique potential. We must use it.

\section{References}

"Academic Advising Programs." CAS Standards, Council for the Advancement of Standards in Higher Education, 2014, http://standards.cas.edu/getpdf.cfm?PDF $=\mathrm{E} 864 \mathrm{D}_{2} \mathrm{C} 4-$ D655-8F74-2E647CDECD29B7Do

Aliakbari, Mohammad and Elham Faraji, "Basic Principles of Critical Pedagogy." IPEDR, vol. 17, 2011, pp. 77-85.

Arnsperger Selzer, Robin and Janelle Ellis Rouse. "Integrating Social Justice and Academic Advising." Academic Advising Today, vol. 36, no. 3, September 2013.

Barlett, Peggy F. and Geoffrey W. Chase. Sustainability on Campus: Stories and Strategies for Change. MIT, 2004.

Bowers, C. A. The Culture of Denial: Why the Environmental Movement Needs a Strategy for Reforming Universities and Public Schools. SUNY, 1997.

Bucci, David, Mary Gabrielsen, Amy Shannon, and Sarah Eberhart. "Save Green by Going Green: Technology to the Rescue." Academic Advising Today, vol. 34, no. 3, September 2011.

Burton, Shannon Lynn, Drew Puroway, Sarah E. Stevens Academic Advising and Social Justice: An Advocacy Approach. NACADA, 2017.

Coll, Jose E. and Carlos J. Zalaquett. "The Relationship of Worldviews of Advisors and Students and Satisfction with Advising: A Case of Homogenous Group Impact.” Journal of College Student Retention, vol. 9, no. 3, 2007-2008, pp. 273-281. 
“Concept of Academic Advising." NACADA, 2017, http://www.nacada.ksu.edu/Resources/Clearinghouse/View-Articles/Concept-of-Academic-Advising.aspx.

“Core Competencies.” NACADA, 2017, https://www.nacada.ksu.edu/AboutUs/NACADA-Leadership/AdministrativeDivision/Professional-Development-Committee/PDC-Advisor-Competencies.aspx

Crookston, Burns B. "A Developmental View of Academic Advising as Teaching." Journal of College Student Personnel, vol. 13, 1972, pp. 12-17.

Dunn, Merrily S. and Jeanne S. Hart-Steffes. "Sustainability as Moral Action.” New Directions for Student Services, no. 139, Fall 2012, pp. 73-82.

Finlay, Linda Shaw and Valerie Faith. "Illiteracy and Alienation in American Colleges: Is Paulo Freire's Pedagogy Relevant?” The Radical Teacher, no. 16, 1980, pp. 28-37.

Freire, Paulo. Pedagogy of the Oppressed. Revised edition. Continuum, 1998.

Giroux, Henry. Pedagogy and the Politics of Hope: Theory, Culture, and Schooling. Westview, 1997.

Goodstein, Eban. The Trade-Off Myth: Fact and Fiction about Jobs and the Environment. Island, 1999.

Hawken, Paul. The Ecology of Commerce. Revised Edition: A Declaration of Sustainability. Collins, 2010.

An Introduction to LEAP: Liberal Education and America's Promise. American Association of Colleges and Universities, 2014.

Jones, Paula, David Selby, and Stephan Sterling. Sustainability Education: Perspectives and Practice Across Higher Education. Earthscan, 2010.

Joslin, Jennifer E. "Toward a Sustainable Advising Practice." Academic Advising Administration: Essential Knowledge and Skills for the 21st Century, edited by Jennifer E. Joslin and Nancy L. Marklee, NACADA, 2011, pp. 275-282.

Kahn, Richard. Critical Pedagogy, Ecoliteracy, and Planetary Crisis: The Ecopedagogy Movement. Peter Lang, 2010.

Kanpol, Barry. Critical Pedagogy: An Introduction. $2^{\text {nd }}$ edition. Bergin \& Garvey, 1999.
Kerr, Kathleen G. and Jeanne S. Hart-Steffes. "Sustainability, Student Affairs, and Students." New Directions for Student Services, no. 137, Spring 2012, pp. 7-17.

Klein, Naomi. This Changes Everything: Capitalism vs. The Climate. Simon \& Schuster, 2014.

Lantta, Melissa. "Supporting Social Justice through Advising." Academic Advising Today, vol. 31, no. 2, 2008.

Leonard, Annie. The Story of Stuff. 2007, https://storyofstuff.org/movies/.

Lowenstein, Marc. "If Advising is Teaching, What Do Advisors Teach?” NACADA Journal, vol. 25, no. 2, Fall 2005, pp. 65-73.

Merchant, Carolyn. Reinventing Eden: The Fate of Nature in Western Culture. Routledge, 2003.

Meyer, Stephen M. "Environmentalism and Economic Prosperity: Testing the Environmental Impact Hypothesis." MIT Project on Environmental Politics and Policy, 1992.

Osbaldiston, Richard and Kennon M. Sheldon. "Promoting Internalized Motivation for Environmentally Responsible Behavior: A Prospective Study of Environmental Goals.” Journal of Environmental Psychology, vol. 23, 2003, pp. 349-357.

"Nested Venn (Figure 1.3)." Sustainability, Wikipedia, https://en.wikipedia.org/wiki/Sustainability.

"Nested Venn (Figure 1.4)." The Three Pillars of Sustainability, Thwink, http://www.thwink.org/sustain/glossary/ThreePillarsOfSustainability.htm.

O’Neill, Saffron and Sophie Nicholson-Cole. “'Fear Won't Do It': Promoting Positive Engagement with Climate Change Through Visual and Iconic Representations." Science Communication, vol. 30, no. 3, March 2009, 355-379.

"Pillars (Figure 1.1)." The Three Pillars of Sustainability, Thwink, http://www.thwink.org/sustain/glossary/ThreePillarsOfSustainability.htm.

"Poll: New American Dream 2014," Center for a New American Dream, 2014, https://newdream.org/resources/poll-2014.

Puroway, Andrew W. "Critical Advising: A FreirianInspired Approach.” NACADA Journal, vol. 36, no. 2, pp. 4-10. 
Schulenberg, Janet K. "Academic Advising Informed by Self-Authorship Theory." In Academic Advising Approaches: Strategies That Teach Students to Make the Most of College. Ed. Jayne K. Drake, Peggy Jordan, and Marsha A. Miller. Wiley, 2013, pages 121-136.

Sheldon, Kennon M., Bryan Garton, Rachael Orr, and Amy Smith. "The Advisor Quality Survey: Good College Advisors are Available, Knowledgeable, and Autonomy Supportive." Journal of College Student Development, vol. 56, no. 3, April 2015, pp. 261-273.

Timpson, William M. et al. 147 Practical Tips for Teaching Sustainability: Connecting the
Environment, the Economy, and Society. Atwood, 2006.

"Venn (Figure 1.2)." The Three Pillars of Sustainability, Thwink, http://www.thwink.org/sustain/glossary/ThreePillarsOfSustainability.htm

Wals, Arjen EJ, and Bob Jickling. " 'Sustainability' in Higher Education: From Doublethink and Newspeak to Critical Thinking and Meaningful Learning." International Journal of Sustainability in Higher Education vol. 3, no. 3, 2002, pp. 221-232.

"What is ESD?" UNESCO, https://en.unesco.org/themes/educationsustainable-development/what-is-esd 